
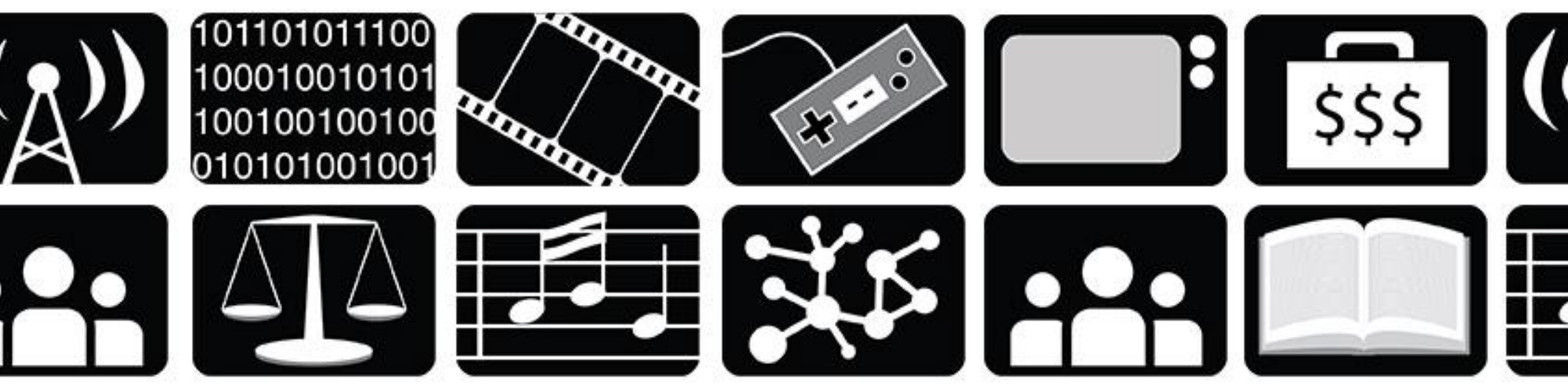

\title{
Welcome to Media Industries
}

\section{The Editorial Collective ${ }^{1}$}

Keywords: Publishing, Scholarly Independence, Research Methods, Internet

Media industry studies has grown substantially since the 1980s as scholars have sought to understand the significance of dramatic transformations in the media landscape. In a historical sense, it was not so long ago that media industries largely comprised tightly regulated institutions in service of a national imaginary. To the extent that their operations crossed borders, their activities were kept under the watchful eye of national guardians. In only a short time we have witnessed the growth and consolidation of huge transnational conglomerates and media infrastructures in virtually every corner of the globe. Relentless pressure from corporate enterprises and financial markets sparked waves of innovation that have profoundly transformed the ways in which media are produced, regulated, distributed, marketed, and consumed. These developments extended the reach of dominant players while simultaneously ushering in a period of unruly innovation that has fostered niche production, DIY creativity, and novel networks of cultural flows. Such interconnected trends have afforded unprecedented circulation for products springing from the margins and opened doors to new modes of exchange that were unimaginable even ten years ago.

These transformations in the media industries have invigorated the scholarly pursuit of new conceptual approaches and innovative methodologies. What was once an area largely characterized by historical, management, quantitative, and political economic studies has become a burgeoning and fully articulated subfield that transcends disciplines and academic societies. Media industry studies has evolved into a truly global endeavor characterized by the proliferation of research sites and a surging expansion of industry-centered programs around the world. The subfield now welcomes discursive, ethnographic, and conjunctural analysis along with investigations of labor practices, networks of production, urban and economic geography, genealogies of media policy and ownership, and the politics of difference in institutional settings and sites of circulation.

Despite this marked growth, it is nevertheless remarkable that media industry studies still lacks a journal specifically dedicated to this rich and diverse literature. With this in mind, members of the Media Industries editorial collective began conversations about the possibility of launching 
such a publication: one that could be as innovative and transformative as the industries it studies. We therefore committed ourselves to a timely, open-access format that would embrace the potential of the online world while honoring the traditions of judicious peer review under the leadership of an esteemed editorial board. We considered this balance between innovation and scholarly tradition to be essential because we wanted our authors to feel comfortable that their scholarship would be widely available online and yet as presentable to tenure and merit review committees as other leading media studies journals.

Media Industries is therefore a peer-reviewed, open-access, online journal promoting critical studies of media industries, institutions, and policies worldwide. We invite contributions that examine the full spectrum of media industries, including but not limited to film, television, internet, radio, music, publishing, gaming, advertising, animation, merchandising, and mobile communications. Submissions may explore these industries individually or examine intermedial relations between industrial sectors through a diverse array of theoretical and methodological approaches ranging from media law and policy to labor studies, from cultural studies to political economy, and everywhere in between. We encourage contemporary and historical studies and are especially interested in contributions that draw attention to global and international perspectives that produce genuinely insightful comparative studies. The journal is furthermore dedicated to the exploration of inventive methodologies, imaginative theoretical approaches, creative uses of the online publishing format, and new research directions.

The ambitious scope outlined above made it clear to us that ongoing operations would require many hands and perspectives. While traditionally journals are operated by one or two managing editors, Media Industries represents an international collaboration among six universities on four different continents: Chinese University of Hong Kong; Georgia State University; the University of California, Santa Barbara; the University of Nottingham; the University of Texas at Austin; and Queensland University of Technology.

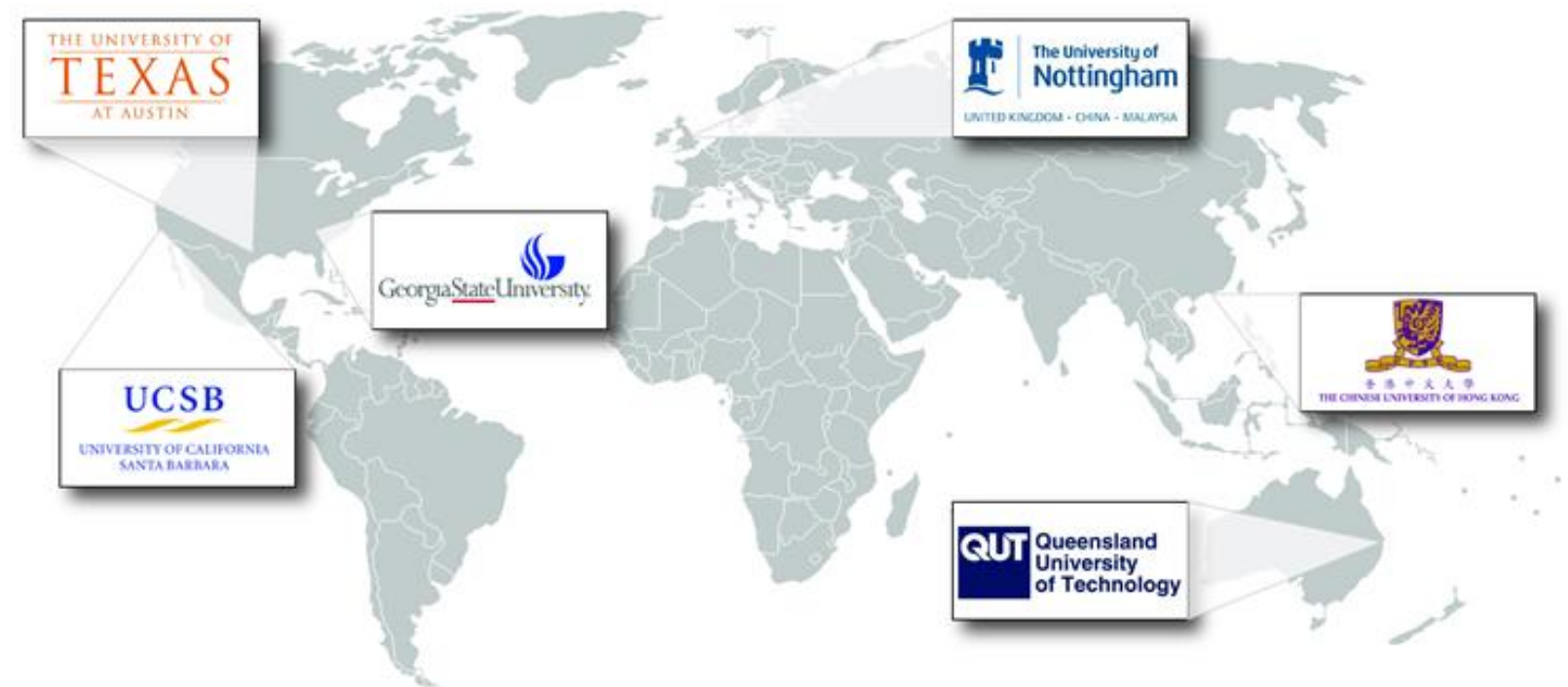

The journal's administrative and editorial processes are managed by leading faculty - what we have termed "the editorial collective" - from these institutions. We paired this editorial collective with an editorial board that also spans the globe. We hope that the geographic and 
theoretical diversity of our leadership as well as the open-access platform will attract submissions and readers from around the world.

Given our genesis and the mission outlined above, we decided to devote the first three issues of Media Industries to short essays contributed by our editorial board. In these commentarieswhich will be published over the next several months - individual board members offer a range of perspectives on the history, current status, and future prospects for media industry studies. Some essays focus on key issues, some on theoretical concerns, and others on methodology. This diversity aims both to represent the richness of this area of study and to invite a genuine variety of contributions for upcoming issues.

We're now open for business, so please send us your submissions, which will be peer reviewed by members of our editorial collective and editorial board. We expect the journal to remain a dynamic entity that will continue to evolve in response to industry and academic trends as well as the world of online publishing. We thus invite our readers to email us with any ideas or suggestions, and we encourage contributors to fully exploit the creative capacities of the internet by including multimedia elements, audiovisual material, and hyperlinks in their submissions. We look forward to your submissions and your engagement with what we believe to be one of the most exciting endeavors in academic publishing.

Sincerely,

The Editorial Collective

Amelia Arsenault, Georgia State University

Stuart Cunningham, Queensland University of Technology

Michael Curtin, University of California, Santa Barbara

Terry Flew, Queensland University of Technology

Anthony Fung, The Chinese University of Hong Kong

Jennifer Holt, University of California, Santa Barbara

Paul McDonald, University of Nottingham

Brian McNair, Queensland University of Technology

Alisa Perren, University of Texas at Austin

Kevin Sanson, University of California, Santa Barbara

${ }^{1}$ The launch of Media Industries would not be possible without the diligent work of our team of graduate research assistants. We would like to acknowledge: Charlotte Howell, a PhD student at University of Texas, Austin who provided invaluable administrative support; Kyle Wrather, an MA student at Georgia State University, who designed the journal logos and website, and supervised the article layout; also MA student Shannan Finke (GSU) and PhD student Claire Shinhea Lee (UT-Austin) for their help with other administrative tasks. 


\section{Forthcoming Essays By the Media Industries Editorial Board}

(by author's last name)

Dirt Research for Media Industries - Charles R. Acland

Work in the Media - Mark Deuze

Media Policy Research and the Media Industries - Des Freedman

The Value of Ethnography - Tejaswini Ganti

On Comparison - Nitin Govil

Media Industries in an Era of Big Audience Data - Timothy Havens

The Menace of Instrumentalism in Media Industries Research and Education - David Hesmondhalgh

Transnational TV: What Do WE Mean by "Co-Production," Anymore? - Michele Hilmes

The Film Festival as Industry Node - Dina Iordanova

Placing International Media Production - Aphra Kerr

Industrialization and Globalization in China's Musical Business - Shin Dong Kim

Media Industries in Revolutionary Time - Marwan M. Kraidy

Media Industries in India: An Emerging Regional Framework - Shanti Kumar

Assembling a Toolkit - Amanda D. Lotz

Welcome to the Unregulated Wild, Wild, Digital West - Denise Mann

Media Industries and Ecological Crisis - Richard Maxwell

Media Work, Management, and Greed: A New Agenda? - Vicki Mayer

"Invisible Work" in the Indian Media Industries - Ranjani Mazumdar

The Discourse on Media is Dominated by Reactionary Cant - Toby Miller

On Automation in Media Industries: Integrating Algorithmic Media Production into Media Industries Scholarship - Philip Napoli

"It's TV's Fault I Am This Way": Learning From Love/Hating the Media Industries - Phil Oppenheim 
Politically Charged Media Sites: The "Right," the "Left," and the Self in Research - Yeidy M. Rivero

Film Studies, Cultural Studies, and Media Industry Studies - Thomas Schatz

Navigating the Two Worlds of Research - James Schwoch

Advertising, the Media, and Globalization - John Sinclair

Selling Television: Addressing Transformations in the International Distribution of Television Content - Jeanette Steemers

There Is No Music Industry - Jonathan Sterne

Global, Regional, Transnational, Translocal - Joe Straubhaar

Globalization through the Eyes of Runners: Student Interns as Ethnographers on

Runaway Productions in Prague - Petr Szczepanik

Where in the World is Orphan Black? Change and Continuity in Global TV

Production and Distribution - Serra Tinic

The Case for Studying In-Store Media - Joseph Turow

Industry Proximity - Patrick Vonderau

Learning from the History of the Field - Janet Wasko

TV, Digital, and Social TV: A Reflection - Jing Wang

The Ramifications of Media Globalization in the Global South for the Study of Media Industries - Herman Wasserman

Home is Where Hollywood Isn't: Re-casting East Asian Film Industries - Emilie Yeh 